\title{
Estimating Probable Maximum Precipitation - From Research to Design
}

\author{
W. C. D. K. Fernando and S. S. Wickramasuriya
}

\begin{abstract}
There are two widely used methods for estimating Probable Maximum Precipitation (PMP), namely, the hydro-meteorological and statistical techniques which are characteristic of the deterministic and probabilistic approaches respectively. International research shows substantial differences in the results obtained by these methods. The present study uses data from several agro-ecological regions of Sri Lanka to estimate 24-hour point PMP. The statistical method is applied in three different ways; with equal sample size, increasing sample size and a continuous data set. Results show that the differences are less than $10 \%$, thus demonstrating consistency and dependability of the method. When compared with the hydrometeorological method, both approaches yield results which are in close agreement at several stations. The wind and moisture maximization factors play a crucial part in the hydrometeorological procedure. Also considering the ease of analysis, the study strongly suggests the statistical method as efficient and appropriate for estimating PMP in design office practice and for developing PMP maps for Sri Lanka. Aspects needing further investigation are also mentioned.
\end{abstract}

Keywords: Probable maximum precipitation, Extreme rainfall, Statistical method, Hydrometeorology

\section{Introduction}

Sri Lanka is susceptible to extreme rainfall and floods due to weather patterns associated with the country's geographical location. One of the worst flood disasters due to extreme rainfall was the flood of May 2003 which severely affected the Ratnapura and Kalutara districts and some areas of the Southern Province. Another devastating flood, which caused serious damages to many irrigation schemes and infrastructure, was the flood of December 1957 in the North Central Province.

Extreme rainfalls can be obtained from meteorological records. Analysis of such rainfall data is vital in the context of public safety. The estimation of extreme values continues to be a challenge in hydrologic design. The concept of ProbableMaximumPrecipitation (PMP) is an attempt made to face this challenge.

PMP is defined as "the theoretically greatest depth of precipitation for a given duration that is physically possible over a particular drainage area at a particular time of year" (WMO [4]).

PMP estimates play a crucial role as essential input data for determining the Probable Maximum Flood (PMF) in the design of spillways of major dams. It is obvious that overestimation of PMP would result in added expenditure while underestimation could result in catastrophic failure. (Bureau of Meteorology Australia [2])

The main objective of this paper is to estimate 24-hour, point PMP by using deterministic and probabilistic approaches for selected meteorological stations of Sri Lanka. Researchers have highlighted a major issue and that is, the two approaches give results which vary substantially. An attempt is also made to investigate the possible causes for the discrepancies.

\section{Background}

Apart from a few stability failures all other significant events related to major dams have been associated with the overtopping of bunds. The major floods of December 1957 caused catastrophic devastation, where 35 major irrigation reservoirs and some 1300 village irrigation systems were seriously damaged (Arumugam [1]).

Following this event, a program to increase the discharge capacities of spillways was undertaken. Apparently the original and

\footnotetext{
Eng. (Mrs). W. C. D. K. Fernando, B.Sc. Eng. (Hons)(Moratuwa), M.Eng. (Moratuwa), AMIE (SL), Lecturer, Department of Civil Engineering, General SirJohn Kotelawala Defence A cademy, Sri Lanka. Eng. (Prof.) S. S. Wickramasuriya, B.Sc. Eng, (Hons) (Moratuwa), Ph.D. (NSW), C. Eng., MIE(SL),AssociateProfessor, Department of Civil Engineering, University of Moratuwa, Sri Lanka.
} 
subsequent design data cannot be found for the older dams and flood safety levels are not known. The Government of Sri Lanka launched the Dam Safety and Reservoir Conservation Program (DS\&RCP) in 2003, to assess the adequacy of spillways at 32 dam sites and investigate other hydraulic, geotechnical and structural aspects related to dam safety. The hydrological component involved the estimation of PMP and PMF at the various dam sites, which were located in different agroecological zones. Some initial work on estimation of PMP has been presented by Wickramasuriya et.al. [20] and Fernando and Wickramasuriya [10].

\section{Literature Review - International Scenario}

The use of the statistical method developed by Hershfield [12, 13] and applied in different countries is summarized as follows.

- Desa and Rakhecha [8] have estimated 24-h point PMP in Malaysia. The frequency factor that is commonly used is between 6.0 and 7.5.

- Rezacova et. al. [17] have estimated the point and area PMP for 1 to 5 days in the Czech Republic. The frequency factors were thought to be high and hence a modified method was developed using a statistical model.

- Recent studies done by Koutsoyiannis [14] have demonstrated this method as a reliable tool in hydrologic design.

- Dhar et. al. [7] and Rakhecha and Soman [16] did a study to determine PMP for 1 and 2 day durations in India. They developed functional relationships between the frequency factor and the mean.
- Riddell [18] estimated 1-2 day PMP in New Zealand by considering the frequency factor as 15 . The statistical method was found to give considerably higher results than the hydrometeorological method.

Recent research on the hydrometeorological approach using data from Malaysia, India and Hong Kong have focussed on estimating point and aerial PMP for various durations. A moisture maximization factor in the range of 1.15 to 1.75 was used while no wind maximization was considered. (Desa and Rakhecha [9], Al-Mamun and Hashim [5], Kulkarni [15] and Chang and Hui [6])

\section{Study Area and Data}

Six meteorological stations covering several agro-ecological zones were selected for the analysis (Table 1). For all stations, daily rainfall data were available from $1895-2005$, but only continuous record lengths were chosen for the analysis. The data were initially checked for consistency and were found to be acceptable.

\section{Methodology}

Various methods to estimate PMP are cited in the literature as follows; (Wiesner [3], WMO [4])

- storm model approach,

- hydrometeorological method,

- generalized data,

- empirical formulae,

- statistical analysis and

- other empirical relationships.

This paper focuses only on two widely used methods; the deterministic approach which is the hydrometeorological method and the statistical approach.

Table 1: General Characteristics of Selected Meteorological Stations

\begin{tabular}{|c|c|c|c|c|c|c|}
\hline \multirow[t]{2}{*}{ Station } & \multirow{2}{*}{$\begin{array}{l}\text { Agro- } \\
\text { ecological } \\
\text { zone }\end{array}$} & \multirow{2}{*}{$\begin{array}{l}\text { Elevation } \\
\text { (m) }\end{array}$} & \multicolumn{2}{|c|}{ Continuous record } & \multirow{2}{*}{$\begin{array}{l}\text { Max. daily } \\
\text { rainfall } \\
(\mathrm{mm})\end{array}$} & \multirow[t]{2}{*}{ Date } \\
\hline & & & $\begin{array}{l}\text { Length } \\
\text { (years) }\end{array}$ & Period & & \\
\hline Anuradhapura & DL 1 & 89.9 & 55 & $1951-2005$ & 319.5 & $31-12-1948$ \\
\hline Galle & WL 4 & 12.5 & 75 & $1931-2005$ & 319.7 & 07-05-1915 \\
\hline Hambantota & DL 5 & 15.5 & 55 & $1951-2005$ & 296.9 & 06-05-1975 \\
\hline Kurunegala & IL 1 & 116.1 & 103 & $1903-2005$ & 249.4 & $25-10-1972$ \\
\hline Puttalam & DL 3 & 2.1 & 111 & $1895-2005$ & 306.3 & $08-05-1883$ \\
\hline Ratnapura & WL 1 & 34.5 & 111 & $1895-2005$ & 394.4 & $15-07-1942$ \\
\hline
\end{tabular}




\subsection{Statistical method}

Hershfield's statistical method is based on the generalized frequency equation,

$\mathrm{X}_{\mathrm{t}}=\overline{\mathrm{X}}+\mathrm{KS}_{\mathrm{n}}$

where $\bar{X}_{t}$ is the rainfall for return period $t$ in years, $\overline{\mathrm{X}}$ and $\mathrm{S}_{\mathrm{n}}$ are the mean and the standard deviation of a series of $n$ annual rainfall maxima of a given duration, and $\mathrm{K}$ is the frequency factor. If PMP is substituted for $\mathrm{X}_{t}$ and $\mathrm{K}_{\mathrm{m}}$ for $\mathrm{K}$ where $K_{m}$ is the highest value of $K$ to yield PMP, then the equation becomes,

$\mathrm{PMP}=\overline{\mathrm{X}}+\mathrm{K}_{\mathrm{m}} \mathrm{S}_{\mathrm{n}}$

Records from 2645 stations of 24-hour rainfall were considered to compute $K_{m}$ and it was found that the maximum observed value of $\mathrm{K}_{\mathrm{m}}$ was 15. (Hershfield [12]) Hence, to estimate PMP, $\mathrm{K}_{\mathrm{m}}=15$ can be substituted in (2). Later, Hershfield [13] considered rainfall durations shorter than 24-hours and constructed a nomograph, which indicates that $\mathrm{K}_{\mathrm{m}}$ varies between 5 and 20 .

The introduction of an unusually large event, which is called an outlier, may have an effect on the mean and standard deviation of the annual series. Therefore, to compensate for outliers, it is necessary to calculate a ratio of means and standard deviations where the numerator does not include the maximum observed event while the denominator includes all values. Hershfield [12] found that a 50-year record could be used as a reference standard to adjust other short records.

Most rainfall observations are made using nonrecording gauges, so that the rainfall during a fixed interval is less than the value during the true interval. Weiss [19] showed that the conversion factor of true amount to observational amount for any time interval of same length to be 1.143 and hence the PMP is adjusted accordingly.

The statistical method was applied on annual maximum daily rainfall series for each of the six stations in three different ways.

- Equal sample size - 50-year sample size

- Increasing sample size - $10,15,20,30,50,100$ (if available)

- A continuous data set - As shown in Table 1

\subsection{Hydrometeorological method}

The goal of the hydrometeorological method, which is recommended by the World Meteorological Organization is to increase the available rainfall data to get maximum possible moisture either "in-situ" or by "transposition". If there are inadequate records of rainfall within the area, then it is possible to transpose storms from other meteorologically homogenous areas to the project area. However, in Sri Lanka, an extensive rainfall network has been maintained and hence this study is limited to in-situ maximization.

In-situ maximization can be done in two ways; namely by incorporating moisture maximization and wind maximization. In many international studies it can be seen that moisture maximization alone is used to adjust the rainfall data. But wind maximization can also be used in non-orographic regions, when moisture maximization gives inadequate or unrealistic results. (WMO [4])

The moisture maximization factor (MMF) is the ratio of the maximum precipitable water $(\mathrm{Wm})$ to the precipitable water for the storm (Ws) where the precipitable water can be used to express the moisture charge.

$\mathrm{MMF}=\mathrm{W}_{\mathrm{m}} / \mathrm{W}_{\mathrm{s}}$

Sea-level dew point temperature is the best tool to evaluate precipitable water and it also can be used for comparison of dew points at different stations and at different elevations. However, the dew point should not be a single reading, but it should persist for hours rather than minutes. In addition, for a storm of D hour duration, it is possible to select the highest $\mathrm{D}$ hour persisting dew point or the highest dew point that can persist for $\mathrm{D}$ consecutive hours. (Wiesner [3])

Precipitable water can be calculated by the summation from sea level to an elevation of $12,200 \mathrm{~m}$ ( $200 \mathrm{mb}$ pressure) by assuming that dew point in an air column changes with the altitude having a pseudo-adiabatic lapse rate. In general, the moisture availability above the elevation $12200 \mathrm{~m}$ is very little and hence not considered. Due to the seasonal monsoon variation the maximum 24-hour persisting dew point is selected by considering only the respective month in which the storm has occurred. 
The wind maximization factor (WMF) is the ratio of the maximum daily wind run for the critical direction $(\mathrm{Fm})$ to the observed daily wind run for the same direction (Fs) in the storm being maximized. Therefore,

$\mathrm{WMF}=\mathrm{F}_{\mathrm{m}} / \mathrm{F}_{\mathrm{s}}$

In Sri Lanka, considering the wind climate, both wind direction and wind speed are largely characterized by the monsoon system. [Fernando, 11] Hence selecting the critical direction plays a vital role in deriving the wind maximization ratio. In addition, to determine the maximum wind speed, a long record of wind observations is necessary. Both maximization factors are used to calculate PMP as follows;

$\mathrm{PMP}=\mathrm{P}_{\mathrm{obs}} \times(\mathrm{MMF}) \times(\mathrm{WMF})$
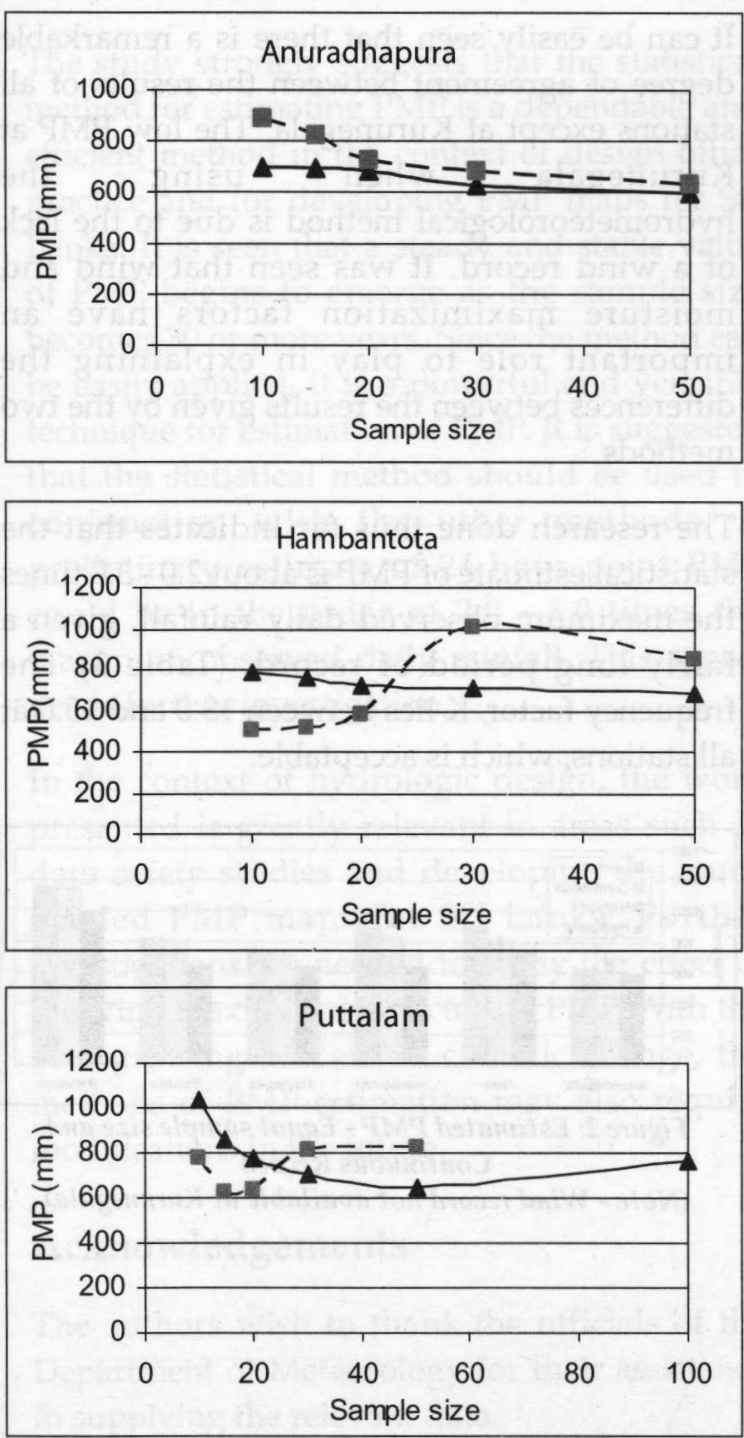

Figure 1: The variation of PMP with increasing sample size where $P_{\text {obs }}$ is the highest observed storm rainfall for a particular duration (24 hours), and PMP corresponds to the same duration.

In the absence of 24-h rainfall, the PMP can be computed by using the highest observed daily rainfall and the Weiss factor as mentioned under the statistical method.

\section{Analysis}

\subsection{Statistical method}

a) Increasing sample size

In this method the statistical procedure was used to estimate PMP with sample sizes of 10 , $15,20,30,50$ and 100 (if available). This enables an increasing maximuin rainfall value to be incorporated into the analysis. (Figure 1)
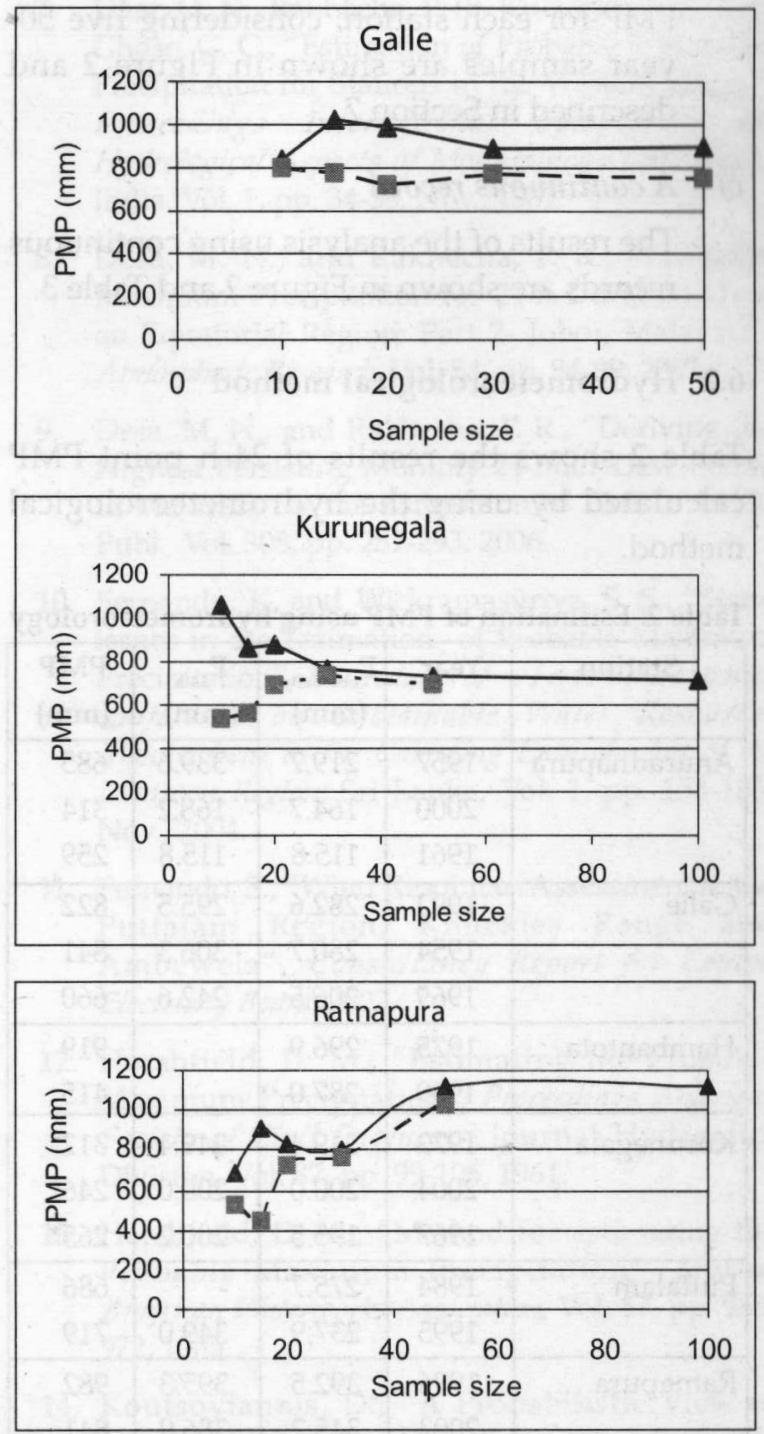

- PMP2 using data from 1951 onwards 
All stations show a convergence (upward or downward) of PMP with increasing sample size. Convergence patterns can change abruptly due to the occurrence of extreme rainfall. Standard deviation has a major influence on the estimated PMP. It can be clearly seen that a stable or steady value for PMP begins to emerge when the sample size is 30 or more. Thus PMP estimates with 50 year and 100 year samples show a close degree of agreement.

\section{b) Equal sample size}

Secondly, all data were divided into equal sample sizes of 50 years. Hershfield [12] used a 50-year record to adjust other short records. For each station five samples were analysed. In this case too the maximum rainfall changes, thus changing the PMP estimate. The lowest and highest values of PMP for each station, considering five 50 year samples are shown in Figure 2 and described in Section 7.

\section{c) A continuous record}

The results of the analysis using continuous records are shown in Figure 2 and Table 3.

\subsection{Hydrometeorological method}

Table 2 shows the results of 24 -h point PMP calculated by using the hydrometeorological method.

Table 2: Estimation of PMP using hydrometeorology

\begin{tabular}{|l|c|c|c|l|}
\hline \multicolumn{1}{|c|}{ Station } & Year & $\begin{array}{c}\mathbf{P}_{\text {obs-daily }} \\
(\mathbf{m m})\end{array}$ & $\begin{array}{c}\mathbf{P}_{\text {24h }} \\
(\mathbf{m m})\end{array}$ & $\begin{array}{l}\text { PMP } \\
(\mathbf{m m})\end{array}$ \\
\hline Anuradhapura & 1957 & 219.7 & 339.6 & 685 \\
& 2000 & 164.7 & 168.2 & 314 \\
& 1961 & 115.8 & 115.8 & 259 \\
\hline Galle & 1992 & 282.6 & 295.5 & 822 \\
& 1954 & 280.7 & 306.3 & 841 \\
& 1969 & 206.5 & 242.6 & 660 \\
\hline Hambantota & 1975 & 296.9 & - & 919 \\
& 1969 & 287.0 & - & 415 \\
\hline Kurunegala & 1972 & 249.4 & 249.4 & $312^{*}$ \\
& 2004 & 200.0 & 200.0 & $246^{*}$ \\
& 1967 & 195.5 & 200.2 & $265^{*}$ \\
\hline Puttalam & 1984 & 275.7 & - & 686 \\
& 1995 & 237.9 & 349.0 & 719 \\
\hline Ratnapura & 1996 & 392.5 & 395.3 & 982 \\
& 2003 & 345.2 & 386.9 & 841 \\
& 1968 & 294.9 & - & $452^{*}$ \\
\hline
\end{tabular}

* No wind maximization factors are available.
The moisture maximization factor is in the range of 1.25 to 1.75 , which is compatible with the literature cited. The wind maximization factor is in the order of 1.8 at four out of the six stations. In the absence of 24-h rainfall, the Weiss factor was used to estimate PMP.

\section{Results and Discussion}

Figure 2 shows the lowest and highest values of PMP considering five equal sized (50 years) samples and the PMP estimated using a continuous length of record, all based on the statistical method. These are compared with the hydrometeorological estimate of PMP.

In statistical analysis, the results of all three methods show that the differences are less than $10 \%$ and thus clearly demonstrate the consistency of the statistical method.

It can be easily seen that there is a remarkable degree of agreement between the results of all stations except at Kurunegala. The low PMP at Kurunegala when using the hydrometeorological method is due to the lack of a wind record. It was seen that wind and moisture maximization factors have an important role to play in explaining the differences between the results given by the two methods.

The research done thus far indicates that the statistical estimate of PMP is about 2.0-3.0 times the maximum observed daily rainfall, given a fairly long period of record. (Table 3 ) The frequency factor, $\mathrm{K}$ lies between 13.0 and 15.0 at all stations, which is acceptable.

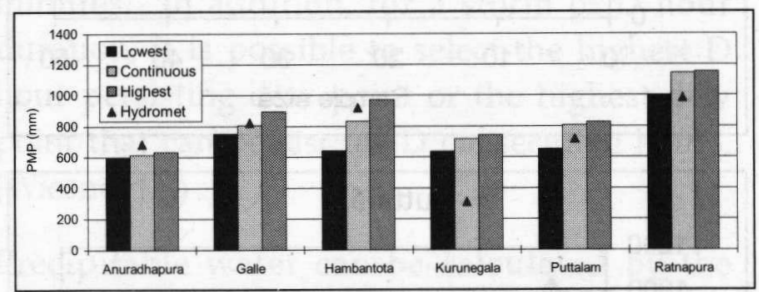

Figure 2: Estimated PMP - Equal sample size and Continuous Record

(Note - Wind record not available at Kurunegala) 
Table 3: Final Comparison of PMP

\begin{tabular}{|l|c|c|c|}
\hline \multicolumn{1}{|c|}{ Station } & $\begin{array}{c}\text { Statistical } \\
\text { PMP (mm) }\end{array}$ & $\begin{array}{c}\text { Hydrome- } \\
\text { teorological } \\
\text { PMP (mm) }\end{array}$ & $\begin{array}{c}\text { PMP } \\
\text { statistical } \\
\text { max.daily } \\
\text { observed }\end{array}$ \\
\hline Anuradhapura & 620 & 690 & 1.9 \\
Galle & 810 & 830 & 2.5 \\
Hambantota & 840 & 920 & 2.8 \\
Kurunegala & 720 & $320^{*}$ & 2.9 \\
Puttalam & 810 & 720 & 2.6 \\
Ratnapura & 1150 & 990 & 2.9 \\
\hline
\end{tabular}

\section{Conclusions}

It is certainly noteworthy to mention that both the statistical and hydrometeorological methods yield results which are in close agreement at all stations except at Kurunegala, where storm maximization incorporates moisture maximization, wind maximization and the true 24hour rainfall.

The study strongly suggests that the statistical method for estimating PMP is a dependable and efficient method in the context of design office practice and for developing PMP maps for Sri Lanka. It is seen that a steady and stable value of PMP begins to emerge as the sample size becomes 30 or more years. Since the method can be easily applied, it is a powerful and versatile technique for estimation of PMP. It is suggested that the statistical method should be used in conjunction with the other methods. A preliminary estimate of 24 hour point PMP could be in the order of 2.0 - 3.0 times the maximum observed daily rainfall. This aspect needs further investigation.

In the context of hydrologic design, the work presented is greatly relevant in areas such as dam safety studies and developing the much needed PMP maps for Sri Lanka. Further investigations are needed to study the effect of the wind maximization factor on PMP. With the ever growing concern of climatic change, the methods of PMP estimation may also require modifications in the future.

\section{Acknowledgements}

The authors wish to thank the officials of the Department of Meteorology for their assistance in supplying the relevant data.

\section{References}

1. Arumugam, S., Water Resources of Ceylon, its utilisation and development, Water Resources Board, Sri Lanka, 1969.

2. Bureau of Meteorology, The Estimation of Probable Maximum Precipitation in Australia: Generalised Short-duration Method, Australia, June, 2003.

3. Wiesner, C. J., Hydrometeorology, Chapman \& Hall Ltd., London, 1970.

4. World Meteorological Organisation, Manual for Estimation of Probable Maximum Precipitation, Operational Hydrology, Rep.1, WMO No. 332, 2nd ed., Geneva, Switzerland, 1986

5. Al-Mamun, A., and Hashim, A., "Generalised Long Duration Probable Maximum Precipitation (PMP) Isohyetal map for Peninsular Malaysia", J. of Spatial Hydrology, Vol. 4, No. 1, spring 2004.

6. Chang, W. L., and Hui, T. W., Probable Maximum Precipitation for Hong Kong, Reprint 482, Hong Kong Observatory, 2001

7. Dhar, O. N., Rakhecha, P. R., Kulkarni, A. K. and Ghose, G. C., "Estimation of Probable Maximum Precipitation for Stations in the Western Ghats", Proceedings International Symposium on Hydrological Aspects of Mountainous watersheds, India, Vol. 1, pp. 34-38, Nov., 1982.

8. Desa, M. N., and Rakhecha, P. R., "Probable Maximum Precipitation for 24-h Duration Over an Equatorial Region: Part 2- Johor, Malaysia", Atmospheric Research, Vol. 84, pp. 84-90, 2007.

9. Desa, M. N., and Rakhecha, P. R., “Deriving the Highest Persisting Monthly 24-hour Dew Points in Malaysia for the Estimation of PMP", IAHS Publ., Vol. 308, pp. 287-293, 2006.

10. Fernando, K. and Wickramasuriya, S. S., "Some issues in the Estimation of Probable Maximum Precipitation", Proceedings of International conference on Sustainable Water Resources Management in the Changing Environment of the Monsoon Region, Sri Lanka, Vol. 1, pp. 153-165, Nov., 2004.

11. Fernando, S., "Wind Resources Assessment in the Puttalam Region, Knuckles Range and Ambewela", Consultancy Report for Ceylon Electricity Board, 2002.

12. Hershfield, D. M., "Estimating the Probable Maximum Precipitation", Proceedings American Society of Civil Engineers, Journal Hydraulics Division, Vol. 87, pp. 99-106, 1961.

13. Hershfield, D, M., "Method for estimating the Probable Maximum Precipitation", Journal American Waterworks Association, Vol. 57, pp. 965972, 1965

14. Koutsoyiannis, D., "A Probabilistic View of Hershfield's Method for Estimating Probable Maximum Precipitation", Water Resources Research, Vol. 35, No. 4, pp. 1313-1322, 1999. 
15. Kulkarni, B. D., "Generalized Approach of Estimating Areal Probable Maximum Precipitation (PMP) for Plain Region of the Godavari River Basin - India", J. of Spatial Hydrology, Vol. 2, No. 2, 2002.

16. Rakhecha, P. R. and Soman, M. K., "Estimation of Probable Maximum Precipitation for a 2-Day Duration:Part 2 North Indian Region", Theoretical \& Applied Climatology, Vol. 49, pp. 7784, 1994.

17. Rezacova, D., Pesice, P. and Sokol, Z., “An Estimation of the Probable Maximum Precipitation for River Basins in the Czech Republic", Atmospheric Research, Vol. 77, pp. 407421, 2005

18. Riddell, D. C., "Flood Hydrology of the Motu River", J. of Hydrology (N. Z.), Vol. 19, No. 1, pp. $35-48,1980$.

19. Weiss, L. L., "Ratio of True to Fixed Interval Maximum Rainfall", Proceedings of the American Society of Civil Engineers, Journal Hydraulics Division, Vol. 90, 1964.

20. Wickramasuriya, S. S., Vanathy, I. and Wickramaratne, S., "Some Hydrological Issues in the Assessment of Dam Safety", Annual Transaction of IESL, 2004. 